\title{
Charles Baudelaire: modernidades segundo Walter Benjamin.
}

\section{Elder João Teixeira Mourão, UFMG}

Resumo: Este trabalho é uma visada sobre texto do filósofo berlinense Walter Benjamin que traça com seu estilo difuso e descontínuo um painel da vida e obra do poeta francês Charles Baudelaire destacando a passagem entre duas épocas - romantismo e modernismo - e a sedimentação da última.

Palavras-chave: romantismo; ruptura; modernidade.

Queremos tanto este fogo, brilha-nos a imaginação flamejante, Mergulhar no fundo do precipício, Inferno ou Céu, o que importa? No fundo do Ignorado para algum novo encontrar!

Charles Baudelaire

Nas Obras escolhidas vol. III - Charles Baudelaire, um lírico no auge do Capitalismo (2a ed., 1991), Walter Benjamin (1892-1940), traça com seu estilo difuso e descontínuo, cheio de ires e vires, muitas citações colhidas de outros textos de sua cepa e de outros autores, um perfil da vida e obra de Baudelaire (1821-1867), um dos mais importantes poetas da língua francesa, responsável pela ocidentalização da até então, salvo raras exceções, pouco expressiva produção poética gaulesa e, cuja poesia transbordada de imagens românticas e rigores clássicos, tornou-o fundador artístico e mentor intelectual da "modernidade" - movimento literário e artístico que a partir do fim do século XIX passaria a designar diversas tendências: cubismo, dadaísmo, futurismo, etc. De fond en comble Benjamin reconhece em ensaio intitulado A Modernidade, incluso na obra supracitada, a tendência do Modernismo a aplicar a crítica histórica, científica e filosófica aos textos literários e na interpretação dos bíblicos. Aspectos referenciais na obra baudelairiana, usa - ele Benjamin - para a sua análise de elementos peculiares da sua produção literária: as faces histórico-culturais e sociológicas, que o fizeram um dos grandes críticos da cultura no século XX.

Charles-Pierre Baudelaire nasceu em Paris e, segundo o Calendário Baudelairiano elaborado por Ivan Junqueira na sua apresentação à tradução d'As Flores do Mal, "à Rua Hautefeuille, esquina com o Boulevard Saint-Germain [a casa foi demolida logo após a abertura deste boulevard, tendo sido seu terreno ocupado pela atual Livraria Hachette" ${ }^{1}$ ]. Herdeiro do romantismo e fiel à prosódia tradicional, ele exprimiu ao mesmo tempo o trágico do destino humano e uma visão mística do universo, onde 
descobriu misteriosas "correspondências". Suas belas "flores doentias" e os Pequenos Poemas em Prosa, ambos publicados em 1857, e sua obra crítica - A Arte Romântica -, postumamente editada em 1868, são a nascente da sensibilidade moderna. Como Wilhelm Apollinaris de Kostrowitzky, chamado Guillaume (18801918) e Henri Beyle, chamado Stendhal (1783-1842), foi também herdeiro de Denis Diderot (1713-1784) e trouxe dele para a sua crítica de arte a coerência dos critérios de avaliação e julgamento onde prevalece a observação contínua e atenta. Não à toa revelou ao mundo Eugène Delacroix (1798-1863) e Constantin Guys (1802-1892) desenhista e aquarelista autor de numerosos testemunhos sobre as guerras e costumes do Segundo Império. Benjamin, no ensaio citado, afirma que "a modernidade assinala uma época; designa ao mesmo tempo a força que age nessa época e que a aproxima da antigüidade" ${ }^{2}$ para completar mencionando as frases finais do crítico de arte Baudelaire em seu estudo sobre o aquarelista: "Por toda a parte buscou a beleza transitória e fugaz de nossa vida presente. O leitor nos permitiu chamá-la modernidade". ${ }^{3}$ De Diderot, parece ter herdado também, o gosto pela flânerie, já que o crítico iluminista tinha por hábito fazer-se personagem de alguns quadros observados e se por a passear por eles dando origem ao que mais tarde alguns teóricos viriam a denominar "l'ekphrasis baladeuse ou excursioniste (véritable excursio littéraire) dispositif par lequel le personnage erre dans le tableau". ${ }^{4}$

\section{III}

Gustave Kahn (1859-1936) - simbolista francês e um dos teóricos do verso livre dizia que "em Baudelaire, o trabalho literário era semelhante a um esforço físico". 5 Baudelaire buscava a palavra nas regiões mais esconsas e obscurecidas da alma, lá onde ela se torna inaudível. Tal como Rainer Maria Rilke (1875-1926) - secretário de Auguste Rodin (1840-1917) - e que deixaria o simbolismo para procurar a significação real da arte e da morte em seus poemas, em Baudelaire a ataraxia nunca foi componente da vida e nem, e especialmente, na luta quando o embate era conformar mito e imagem. Trata-se segundo Benjamin da "metáfora do esgrimista". ${ }^{6}$ De posse do florete, Baudelaire duela com as palavras até a exaustão. Nos quatro últimos versos da primeira estrofe do poema II dos Quadros Parisienses, intitulado $O$ Sol, o poeta descreve assim essa luta em que não tem adversário:

Exercerei a sós a minha estranha esgrima,

Buscando em cada canto os acasos da rima,

Tropeçando em palavras como nas calçadas,

Topando imagens desde há muito já sonhadas. ${ }^{7}$

Em texto intitulado Do heroísmo da vida moderna para o Salão de 1859, o crítico Baudelaire além de tratar do artista, trata também do público moderno, da fotografia e da imaginação. O choque causado com a publicação d 'As Flores do Mal estabelece segundo Victor Hugo (1802-1885) - outro célebre precursor da modernidade na França - o marco divisório entre a poesia romântica e a moderna. É no entender de Walter Benjamin a ponte entre o presente e o futuro erguida sobre as ruínas do passado. Esse compromisso com o passado e o abandono do sentimentalismo romântico trazem à poesia baudelairiana a elegância e a predisposição de espírito para a tristeza ou o tédio indissociáveis a todo dândi e marcas da modernidade. 
Dono de muitas máscaras, a ponto de ser acusado pelo pintor Gustave Courbet (1819-1877) - autor do famoso portrait de 1849 - de cabotino, o dandismo baudelairiano para Walter Benjamin é uma manifestação onde o herói não cabe mais e revela-se como dândi. Mais uma de suas encenações, ao poeta da modernidade agrada a referência de François René Chateaubriand (1768-1848) a dândis índios em seu livro Voyage en Amérique (1827) onde o poder da imaginação e a clareza do estilo do escritor que era também visconde une a paixão às descrições das cores, tal como a criação dos ingleses para aqueles que aliaram, segundo Benjamin, "a reação fulminante a atitudes e mímicas relaxadas e mesmo indolentes" 8 dos operadores da Bolsa de Londres. Do mesmo modo, continua Benjamin, "um freqüentador de bulevares parisienses imaginava a figura do dândi londrino, assim ele se refletia fisionomicamente em Baudelaire" (idem). Esta encenação corresponde a uma idéia muito clara de Charles-Pierre sobre a vulgaridade das coisas naturais expressa por ele no fragmento XVII das Fusées: "toujours vulgaire, c'est-à-dire, le contraire du dandy". ${ }^{9}$ Daí pode-se compreender o comportamento refinado do homem e do esteta que foi o grande poeta da República da Letras. Na Arte Romântica (1868) Baudelaire aborda e soluciona o problema do dândi: "A palavra dândi implica uma quintessência de caráter e uma inteligência tênue de todo o mecanismo do mundo". ${ }^{10}$ A elegância do texto baudelairiano pode ser confirmada em outro de seus muitos escritos onde a "inteligência tênue" pode ser observada. Da solidão com a qual Delacroix defendia-se com a frieza dos gestos e o sorriso enigmático, que tanto atraíam as mulheres, sem que nenhuma delas tivesse jamais preenchido a intensidade de seus sentimentos a não ser por breves períodos, escreveu Baudelaire, citado por Célia Maria Marinho Reis na apresentação do volume Mestres da pintura Delacroix (1978): "Ele considerava a mulher como um objeto de arte, delicioso e próprio para exercitar o espírito, mas um objeto de arte desobediente e perturbador". ${ }^{11}$

\section{V}

O mundo das correspondências sempre fascinou Baudelaire e, das relações estabelecidas por ele podemos citar com mais ênfase Antigüidade/Modernidade, Terra/Céu, Deus/Satã, cores/sons, sementes do que viria a ser o Surrealismo e que, nada mais são os frutos da sua existência e experiência urbanas, das perambulações pelas ruas movido a alucinógenos que lhe proporcionavam sensações de transitoriedade, sabe-se lá, tais como aquelas experimentadas pelo filósofo berlinense e descritas por ele em Haxixe em Marselha. Se a Modernidade baudelairiana requer uma saudade da Antigüidade, é possível concatenar que para o poeta francês eterno e transitório também se entrelaçam. Em A Modernidade de Baudelaire (1988), Teixeira Coelho, usando, às vezes, algumas expressões do poeta, define o que foi para o crítico aquela época de transição:

Baudelaire chamará de "Modernidade" esse algo resultante da operação de extrair da moda o que ela tem de poético no histórico, (...). Modernidade feita de "belezas passageiras e fugazes", como se encontram "na vida presente", mas que para transformar-se em obra de arte precisa recorrer à identificação daquilo que estabelece, com a tradição e a continuidade, uma ponte visível. ${ }^{12}$ 
Benjamin, citando novamente Baudelaire no mesmo ensaio, menciona o que o poeta francês assinalou sobre o compositor alemão Richard Wagner (1813-1883): "Se Wagner, na escolha de seus temas e no seu proceder dramático, se aproxima da antigüidade, torna-se, graças à sua força de expressão apaixonada, o representante mais importante da modernidade". ${ }^{13}$

Por extensão, Baudelaire vislumbra a imagem de um mundo visível enquanto correspondência de um outro invisível e superior. Ctonos é segundo o Dicionário de Símbolos (Chevalier e Gheerbrant, 1991) - "nome dado à Terra, mãe dos Titãs e morada dos mortos e dos vivos, é o baixo, por oposição ao alto; a terra sob seu aspecto interno e obscuro, o caráter noturno da esposa, da mãe, do antro"14 - e seria uma cópia imperfeita e inacabada de Urano -"Deus do Céu, na teogonia de Hesíodo; símbolo de uma proliferação criadora em medida e sem diferenciação, que destrói por sua própria abundância, tudo o que engendra". ${ }^{15}$ No quarto poema de Spleen e Ideal - soneto Correspondências, percebe-se muitas dessas relações simbólicas:

A Natureza é um templo onde vivos pilares

Deixam filtrar não raro insólitos enredos;

O homem o cruza em meio a um bosque de segredos

Que ali o espreitam com seus olhos familiares.

Como ecos longos que à distância se matizam

Numa vertiginosa e lúgubre unidade,

Tão vasta quanto a noite e quanto a claridade.

Os sons, as cores e os perfumes se harmonizam.

\section{$[\ldots]$}

Que a glória exaltam dos sentidos e da mente.

Nota-se no soneto as questões plásticas, sonoras e olfativas em inter-relação e a conseqüente recriação da linguagem poética. O texto benjaminiano por si só um mosaico encontra ecos - propositalmente? - no puzzle baudelairiano composto de infinitas peças e, nada mais importante para compreender a sua modernidade que os Quadros Parisienses onde o poeta mistura-se à multidão da cidade contemporânea, caótica, efervescente e onírica, extasiada, mas agônica em suas fantasmagorias. Uma multidão que é a fonte de toda a criação baudelairiana.

\section{VI}

Walter Benjamin, leitor de Baudelaire, não poderia deixar de mencionar a profunda admiração do Poeta pelo seu conterrâneo e contemporâneo Charles Méryon (1821-1868) um ex-oficial da marinha que depois de abandonar o azul dos oceanos dedicou-se a "pintar a sombria majestade da mais inquietante das capitais". ${ }^{16} \mathrm{O}$ gravador, autor de uma série de águas-fortes sobre a capital francesa, registrou as mudanças ocorridas em Paris à época da administração (1853-1870) do barão Georges Haussmann (1809-1891) e que transformariam a face da cidade para sempre proporcionando em Baudelaire as sensações de interpenetração dos tempos idos e 
vindouros que aqueles hojes preparavam. Sobre o assunto Benjamin assim se manifesta:

Porque também em Méryon se interpenetram a antigüidade e a modernidade; também em Méryon se manifesta inconfundivelmente a forma dessa superposição, que é a alegoria. Em suas gravuras, a legenda é importante. Se a loucura tem participação no texto, sua obscuridade apenas sublinha o "significado". ${ }^{17}$

É o caso do título de certas gravuras que trazem em si o sentido figurado de uma água-forte - conceito, pensamento, descrição, notáveis pela expressão vigorosa, direta, incisiva e, até mesmo, da exposição de um pensamento sob forma figurada, que é o primeiro significado de uma alegoria. São exemplos A Torre do Relógio e $O$ Necrotério. Baudelaire escreveu sobre o vigor e a beleza dos desenhos de Méryon:

Raramente vi representada com mais poesia a solenidade natural de uma cidade imensa. As majestades de pedra edificada, os campanários indicando o céu, os obeliscos da indústria,

vomitando para o firmamento blocos de fumaça, (...) o corpo sólido da arquitetura com sua própria arquitetura vazada de uma beleza tão paradoxal (...); nenhum dos elementos complexos que compõem o doloroso e glorioso cenário da civilização fora esquecido. ${ }^{18}$

Fatalidade, Benjamin lembra que além de terem nascido em 1821, morrido com diferença de poucos meses, Méryon louco e Baudelaire afásico e, terem ficado famosos postumamente, Baudelaire foi dos poucos que Méryon teve em vida como admirador e defensor. Lembra também que Baudelaire quis conformar a imagem do herói à do conspirador. Inconscientemente Benjamin também o quis e, dono de uma obra cheia de correspondências alegóricas, tardiamente reconhecida como a baudelairiana, teve o mesmo fim trágico.

Résumé: Ce travail est une visée du texte du philosophe berlinois Walter Benjamin qui trace avec son style diffus et discontinu un tableau de la vie et de l'oeuvre de poète français Charles Baudelaire mettant en lumière le passage entre deux époques - le romantisme et le modernisme - et la sédimentation de la dernière.

Mots-clé: romantisme; rupture; modernité.

\section{Referências Bibliográficas}

BAUDELAIRE, Charles. A modernidade de Baudelaire. Trad. Suely Cassal. Rio de Janeiro: Paz e Terra, 1988. 
BAUDELAIRE, Charles. As flores do mal. Trad. Ivan Junqueira. Rio de Janeiro: Nova Fronteira, 1985.

BENJAMIN, Walter. Charles Baudelaire um lírico no auge do capitalismo. 2. ed. Trad. José Carlos Martins Barbosa; Hemerson Alves Baptista. Rio de Janeiro: Brasiliense, 1994. (Obras escolhidas, 3).

BREGANTINI, Dayse et al. Dossiê Baudelaire. Cult, São Paulo, n. 73, p. 43-57, 2003.

BREGANTINI, Dayse et al. Dossiê Walter Benjamin. Cult, São Paulo, n. 106, p. 45-63, 2006.

CHEVALIER, Jean; GHEERBRANT, Alain. Dicionário de símbolos. 4. ed. Trad. Vera da Costa e Silva et al. Rio de Janeiro: José Olympio, 1991.

COELHO, Teixeira. Apresentação. In: BAUDELAIRE, Charles. A modernidade de Baudelaire. Trad. Suely Cassal. Rio de Janeiro: Paz e Terra, 1988.

JUNQUEIRA, Ivan. Apresentação. In: BAUDELAIRE, Charles. As flores do mal. Trad. Ivan Junqueira. Rio de Janeiro: Nova Fronteira, 1985.

LOUVEL, Liliane. Nuances du pictural. Poétique, Paris, n. 126, p. 175-189, 2001.

REIS, Célia Maria Marinho. Mestres da pintura Delacroix. São Paulo: Abril Cultural, 1978.

\section{Notas}

${ }^{1}$ JUNQUEIRA. Apresentação, p. 14

${ }^{2}$ BENJAMIN. Charles Baudelaire um lírico no auge do capitalismo, p. 80.

3 BAUDELAIRE apud BENJAMIN. Charles Baudelaire um lírico no auge do capitalismo, p. 80.

${ }^{4}$ LOUVEL. Nuances du pictural, p. 185

${ }^{5}$ KAHN apud BENJAMIN. Charles Baudelaire um lírico no auge do capitalismo, p. 68.

${ }^{6}$ BENJAMIN. Charles Baudelaire um lírico no auge do capitalismo, p. 68.

${ }^{7}$ Todos os poemas foram extraídos da tradução de 1985 feita por Ivan Junqueira.

${ }^{8}$ BENJAMIN. Charles Baudelaire um lírico no auge do capitalismo, p. 94.

${ }^{9}$ BAUDELAIRE apud JUNQUEIRA. Apresentação, p. 55.

${ }^{10}$ BAUDELAIRE apud JUNQUEIRA. Apresentação, p. 57 (tradução minha).

${ }^{11}$ BAUDELAIRE apud REIS. Mestres da pintura Delacroix, p. 17-18.

${ }^{12}$ COELHO. Apresentação, p. 14-15.

13 BAUDELAIRE apud BENJAMIN. Charles Baudelaire um lírico no auge do capitalismo, p. 80.

14 BAUDELAIRE apud BENJAMIN. Charles Baudelaire um lírico no auge do capitalismo, p. 317.

15 BAUDELAIRE apud BENJAMIN. Charles Baudelaire um lírico no auge do capitalismo, p. 921-922.

${ }^{16}$ BAUDELAIRE. A modernidade de Baudelaire, p. 137.

${ }^{17}$ BENJAMIN. Charles Baudelaire um lírico no auge do capitalismo, p. 86.

${ }^{18}$ BAUDELAIRE. A modernidade de Baudelaire, p. 136. 